\title{
On Addressing Design Issues That Hinder Reusability of Learning Objects in Instruction Design
}

\author{
Joab E. Agaba and Jude T. Lubega
}

\begin{abstract}
A good number of repositories equipped with millions of standard-based learning objects exist and this presents a great boost in instruction design based on learning objects. However, instructional designers face a number of challenges in reusing these learning objects. This paper presents the design issues that hinder reusability of learning objects and proposes the approaches that can be used to address them.
\end{abstract}

Index Terms-Instruction design, learning objects, reusability, learning object transparency.

\section{INTRODUCTION}

Reference [1] defines instruction design process as the "systematic development of instructional specifications using learning and instructional theory to ensure the quality of instruction." Reference [1] further suggests that instructional design process is the "entire process of analysis of learning needs and goals and the development of a delivery system to meet those needs" and includes the development of instructional materials and activities and tryout and evaluation of instruction and learner activities.

Reference [2] defines reuse as "using components of one product to facilitate the development of a different product with different functionality". Thus, in this research we define reusability of instructional content as the likelihood that the instructional content designed can be used in different ways to achieve different learning objectives with little or no modification.

Just as how reuse of software components in software engineering "may lead to considerable productivity improvements, and consequently, cost savings" [3], so is reuse of instructional content in instructional design. As long as the terms and conditions of reusing the instructional content are not violated by the instruction designer, reusing existing instructional content to produce new content saves a considerable amount of time and other resources that would have been required to design the instructional content from scratch.

Any instruction design process should be guided by a model and reference [4] suggests about 7 instruction design models among which is the E-Instruction model. This model supports a modular course structure where instructional content is a collection of reusable learning objects and these learning objects are organized following existing sound behaviorist or cognitivist design principles like the traditional

Manuscript received June 14, 2013; revised September 6, 2013.

Joab E. Agaba is with College of Computing and Information Sciences, Makerere University, Uganda (e-mail: jagaba@cit.mak.ac.ug).

Jude T. Lubega is with School of Computing and Engineering, Uganda Technology and Management University, Uganda (e-mail: jlubega@utamu.ac.ug ).
Gagne's 9 steps of instruction [5]. The learning object in this case is the set of instructional resources (digital or non-digital) that can be used (and reused) in designing instructional materials [6].

This paper is part of research on how to improve reusability in instruction design through adaptation of learning objects with multi-format assets and it attempts to present the design issues that hinder the reusability of learning objects in instruction design and propose how they can be addressed. Section II presents the learning object as used in instruction design, Section III presents the design issues that hinder reusability of learning objects, and Section IV presents the proposed approaches to address the design issues in Section III and Section V presents conclusions and future work.

\section{THE LEARNING OBJECT IN INSTRUCTION DESIGN}

\section{A. Learning Object Defined}

The origins of the term learning object can be traced way-back in 1994 when it was first coined by Wayne Hodgins during his research at the Computer Education Management Association (CEMA) working group[7]. However, over the years, this term has been defined by a number of individual scholars and standards organizations. The definitions for the learning object available focus on how the concept has been used in instruction design and delivery [8]. For example, reference [6] defines a learning object as "any digital resource that can be reused to support learning", reference [9] defines a learning object as "a digital, self-contained, reusable entity with a clear learning aim that contains at least three internal changing components: content, instructional activities, and context elements", while the standard for Learning Object Metadata[10] developed by the IEEE's Learning Technology Standards Committee (LTSC) defines a learning object as "any entity - digital or nondigital - that may be used for learning, education or training".

\section{B. Standard Structure of a Learning Object}

Every learning object must have two key important parts, namely; the content and the metadata. The content is what the author intends to deliver as knowledge to the learner while the metadata is the data about the content in the learning object. The importance of the metadata is to make learning objects easily discovered from the repositories.

Various standards have been defined by different educational standards organizations such as IMS Content Packaging standard, IEEE LOM standard, Dublin Core standard, CanCore standard, SingCore standard, among others [11] to ensure a standard-based structure for the learning objects developed so as to make them more reusable 
in various ways in instruction design. Among the above stated standards, the IEEE LOM standard is the mostly used standard by various learning object repositories [11], [12] and this standard uses a set of nine metadata attributes to define the descriptive, structural and semantic features of a learning object [13], [14]. Table 1 below presents a summary of the nine metadata attributes that describe the structure of a learning object.

TABLE I: IEEE's LOM ATTRIBUTES [10]

\begin{tabular}{|l|l|}
\hline Attribute & Explanation \\
\hline Life cycle & $\begin{array}{l}\text { The history and current state of this } \\
\text { learning object }\end{array}$ \\
\hline Deneral & $\begin{array}{l}\text { Description of the learning object as a } \\
\text { whole }\end{array}$ \\
\hline Technical & Information about the metadata instance \\
\hline Educational & $\begin{array}{l}\text { Technical requirements and technical } \\
\text { characteristics }\end{array}$ \\
\hline Rights & Educational and pedagogic characteristics \\
\hline Relation & $\begin{array}{l}\text { Intellectual property rights and conditions } \\
\text { of use }\end{array}$ \\
\hline Annotation & The relationship with other learning objects \\
\hline Classification & $\begin{array}{l}\text { Comments on the educational use of the } \\
\text { learning object }\end{array}$ \\
\hline
\end{tabular}

\section{DESIGN ISSUES THAT HINDER REUSABILITY OF LEARNING OBJECTS}

The design of the learning object determines a lot on how it will be reusable and this is inbuilt during instruction design. Some learning object repositories are strict on learning object designers to follow a given standard. For example, repositories like ARIADNE, SMETE, Learning Matrix, iLumina, MERLOT, HEAL, CAREO, Learn-Alberta and Lydia are strict on IEEE LOM standard while EdnA is strict on DublinCore[12]. Much as existing standards provide the required metadata elements, there are some design issues that hinder the reusability of the learning objects. Below are some of such design issues.

\section{A. Transparency of the Learning Object}

Transparency of a learning object means the level at which the instructional designer accesses the learning object; either at interface level, source code level or both. Transparency of learning objects can be considered in three ways, namely:

1) White-box learning objects. Such learning objects provide access to the internal implementation of the learning object (that is, the knowledge of the source code) Normally, white-box learning objects are language specific and overly invasive [15]. An example of a white-box learning object could be a Java Applet source code file for a simulation of an experiment.

2) Black-box learning objects. Such learning objects limit users to operate at the interface level [16] while hiding implementation details. This makes such learning object less reusable as it limits users while adapting them. An example here could be a Java application executable file for a simulation experiment that does not provide access to its source code.

3) Grey-box learning objects. Such learning objects combine features of both white-box and black-box learning objects. In other words, such a learning object can give the users access to its internal implementation while operating at the interface level. An example here could be a Java Applet for a simulation experiment on a Web page whose source code can be downloaded from that Web page.

The Fig. 1 below shows how the transparency of the learning object affects its reusability in instruction design.

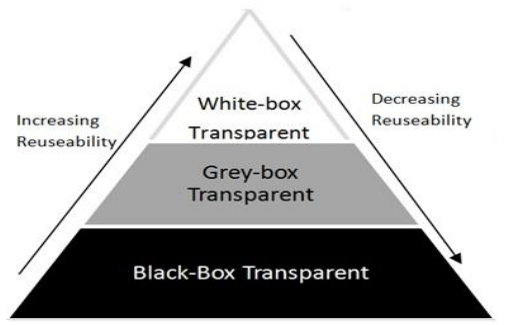

Fig. 1. Transparency triangle for reusability of learning objects in instruction design.

From Fig. 1 above, the more transparent the learning object is the more it can easily be customized or adapted for reuse in instruction design. White-box learning objects are more reusable because both external characteristics and internal implementation of the learning object are available while black-box learning objects are less reusable because only the external characteristics are available.

\section{B. Non-Conformance to Design Standards}

Just as how software components design must follow a given design standard for easy integration in components-based software engineering, so is a learning object's design for reuse in instruction design. A learning object whose design does not follow a given international standard will hardly integrate with other learning objects that are standard-based. Existing learning object metadata standards like IEEE LOM clearly state the metadata elements that must be well defined for each learning object. Well defined and detailed metadata elements of the learning object will make it easy for the instruction designer to reuse that learning object in different ways.

\section{Granularity of the Learning Object}

Reference [17] defines granularity of a learning object as "a process that involves breaking down educational content into a set of items or blocks having a pedagogical sense, also called grain". This definition means that the learning object can be as small as possible provided it remains with "a pedagogical sense".

Reference [18] defines granularity of the learning object in terms of time and suggests that a learning object should take not more than 15 minutes but does not state the minimum time. Reference [19] supports the definition of granularity suggested in [18] by stating that a learning object should be a small learning unit with a duration of between 2 minutes to 15 minutes. However, all these definitions are based on the individual conceptualization of the learning object concept.

Although there is no agreed standard size of a learning object, smaller learning objects tend to be more reusable than larger learning objects [6], [17], [20]. Even the existing standards do not clearly state the standard size of the learning object. For example, SCORM (Sharable Content Object Reference Model) does not recommend any standard size of 
the learning object but states that assets (the basic building blocks of a learning object such as text, animations, images, videos, to mention but a few) are joined to form a sharable content object which is the lowest level of granularity of a single learning resource and SCORM states that both assets and sharable content objects may be reused. Another example is the IEEE's LTSC content model[10] which does not state any standard size of the learning object but presents four levels of learning object aggregation in its LOM standard where level one has raw media data (which we can refer to assets as defined in SCORM), the second level up the hierarchy of the LOM standard in size is a lesson which is a collection of level one assets, the third level being a course which is a collection of lessons in level two and the fourth level being a set of courses that can lead to a certificate.

Lastly, the Cisco Systems RLO content model attempts to define the standard size of a reusable learning object as a combination of five to nine (7 plus or minus 2) Reusable Information Objects(RIO) where a RIO is "a reusable granule of information that is built around a single learning objective" [17]. However, this model does not state the actual size of the RIO meaning that the actual size of the learning object will also vary depending on the size of the RIOs that make it. Thus the smaller the learning object the more reusable that learning object will be in instruction design, keeping other factors constant.

Table II below presents a summary of the suggestions from existing standards about granularity of a learning object.

TABLE II: SUMMARY OF SUGGESTIONS ON GRANULARITY OF LEARNING OBJECT FROM SOME OF THE EXISTING DESIGN STANDARDS

\begin{tabular}{|c|c|}
\hline $\begin{array}{l}\text { LODesign } \\
\text { Standard }\end{array}$ & Suggestion on L0 size \\
\hline SCORM & $\begin{array}{l}\text { No particular size recommended. } \\
\text { But states that assets are joined to form a sharable content object } \\
\text { which is the lowest level of granularity of a single learning resource } \\
\text { and SCORM states that both assets and sharable content objects may } \\
\text { be reused. }\end{array}$ \\
\hline $\begin{array}{l}\text { IEEE's LTSC } \\
\text { content model }\end{array}$ & $\begin{array}{l}\text { No standard size stated but provides } 4 \text { levels LO aggregation. Level } 1 \\
\text { (assets), level 2(lesson or collection of assets), level } 3 \text { (course or } \\
\text { collection of lessons) and level } 4 \text { (a set of courses leading to a } \\
\text { certificate). }\end{array}$ \\
\hline $\begin{array}{l}\text { Cisco Systems } \\
\text { RLO content } \\
\text { model }\end{array}$ & $\begin{array}{l}\text { Attempts to define the standard size of a reusable LO as a combination } \\
\text { of five to nine (7 plus or minus 2) Reusable Information Objects(RIO). } \\
\text { - RIO means "a reusable granule of information that is built around a } \\
\text { single learning objective" (Battou et al.,2011). } \\
\text { - But actual size of RIO not stated, meaning that the size of the LO } \\
\text { depends on the size of the RIO. }\end{array}$ \\
\hline
\end{tabular}

\section{Platform Dependent Learning Objects}

A platform dependent learning object is that learning object that is designed to run/operate on a particular platform (for example a particular operating system). A platform dependent learning object will limit the instructional designer on how many other learning objects it can be integrated with to prepare content for a lesson. This hinders its reusability. However, platform independent learning objects are not tied to a particular platform and thus are more reusable. For example, a learning object designed to run as a Java applet can run on any platform provided that platform is Java-enabled.

\section{E. Learning Objects with Unclear Objectives}

According to the definition of a learning object presented in II (1) above, it should aim at achieving a learning objective. Reference [21] suggests that a learning objective should answer the question "what is it that your students should be able to do at the end of the hour that they could not do?" Reference [21] further suggest that the learning objective in instruction design should contain "action verbs that are specific, such as list, describe, report, compare, demonstrate and analyze" and these should help the instructional designer to describe the behaviors students should have after class. These suggestions clearly indicate that a learning object with poorly presented learning objective in its design might mislead the instructional designer while integrating it into the instructional materials. In short, the values of the attributes of the learning object metadata should match with what actually the learning object is.

\section{F. Separating Pedagogy from the Learning Object}

The learning object and its pedagogy should never be separated. Reference [22] suggests that removing pedagogy from the learning object makes it less reusable by the instructional designer.

\section{Proposed Approaches to AdDRESS THE DESIGN ISSUES THAT HINDER REUSABILITY OF LEARNING OBJECTS}

TABLE III: PROPOSED APPROACHES TO ADDRESS THE DESIGN ISSUES THAT HINDER REUSABILITY OF LEARNING OBJECTS

\begin{tabular}{|c|c|}
\hline Design Issue & Proposed approaches to address it \\
\hline $\begin{array}{l}\text { Transparency of the } \\
\text { learning object }\end{array}$ & $\begin{array}{l}\text { The learning object designer should try to make the } \\
\text { learning object as transparent as possible during its } \\
\text { design. Providing the external characteristics and } \\
\text { internal implementation enables the instructional } \\
\text { designer to easily customize or adapt that learning } \\
\text { object for reuse. The challenge here could be that } \\
\text { the learning object designer may not be willing to } \\
\text { reveal the internal implementation of the learning } \\
\text { object due to copyright reasons. }\end{array}$ \\
\hline $\begin{array}{l}\text { Non-conformance to } \\
\text { design standards }\end{array}$ & $\begin{array}{l}\text { The learning object designer should try to follow } \\
\text { the design standards of the target repository. All the } \\
\text { metadata elements of the learning object (according } \\
\text { to the metadata standard required by the repository) } \\
\text { should be clearly defined to enable the learning } \\
\text { object easily integrate with other standard-based } \\
\text { learning objects in instruction design. }\end{array}$ \\
\hline $\begin{array}{l}\text { Granularity of the } \\
\text { learning object }\end{array}$ & $\begin{array}{l}\text { Since there is no agreed standard size of the } \\
\text { learning object, the learning object designer should } \\
\text { try to make the learning object as small as possible } \\
\text { while ensuring that it remains with a pedagogical } \\
\text { sense. }\end{array}$ \\
\hline $\begin{array}{l}\text { Platform dependent } \\
\text { learning objects }\end{array}$ & $\begin{array}{l}\text { The technical attribute of the learning object's } \\
\text { metadata (see Table I above) should be well } \\
\text { checked to ensure that the learning object is not tied } \\
\text { to any particular platform. }\end{array}$ \\
\hline $\begin{array}{l}\text { Learning objects } \\
\text { with unclear learning } \\
\text { objective }\end{array}$ & $\begin{array}{l}\text { The learning object designer should try to ensure } \\
\text { that the values of the metadata attributes of the } \\
\text { learning object are clear and reflect what the } \\
\text { learning object actually is. This will enable the } \\
\text { instructional designer to select the rightful learning } \\
\text { object from the repository. }\end{array}$ \\
\hline $\begin{array}{l}\text { Separation of } \\
\text { pedagogy from the } \\
\text { learning object }\end{array}$ & $\begin{array}{l}\text { No matter how small or large the learning object is, } \\
\text { the learning object designer should ensure that it } \\
\text { continues carrying its pedagogy. This will enable } \\
\text { the instructional designer to know how the learning } \\
\text { object will be integrated into the existing content } \\
\text { and delivered to the learner without compromising } \\
\text { the learning objectives of the course. }\end{array}$ \\
\hline
\end{tabular}


In Table III, we present the proposed approaches to address the design issues that hinder reusability of learning objects in instruction design.

Fig. 2 below presents the proposed methodology that helps to check design issues in order to improve reusability of learning objects in instruction design. The methodology assumes that the learning object designer is already in the process of learning object design and thus focuses on checking for design issues in order to produce a reusable learning object.

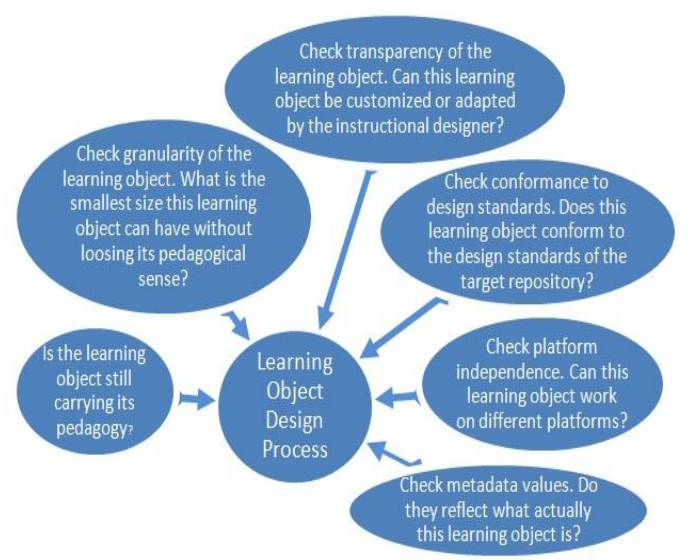

Fig. 2. The proposed methodology for checking design issues to improve reusability of learning objects in instruction design.

\section{CONCLUSIONS AND FUTURE WORK}

With the availability of numerous learning objects stored in various online repositories, instructional designers should embrace reuse than design from scratch. This reuse of learning objects in instruction design can be further improved if the learning object designers can address the design issues that hinder reusability before posting their learning objects into repositories. In this paper, we have identified some of the design issues and also proposed approaches on how to address them. In future research, we will investigate how learning objects are adapted for reuse in instruction design and further develop a model for adaptation of learning objects with multi-format assets in order to improve reuse in instruction design.

\section{REFERENCES}

[1] C. Berger and R. Kim, "Training and Instruction Design," Applied Research Laboratory, Penn State University.

[2] S. R. Schach, Object-Oriented and Classical Software Engineering, New York: McGraw-Hill,Inc, pp. 216, 2007.

[3] Centurion Enterprises. Software Reusability. [Online]. Available: http://centurion2.com/SEHomework/SoftwareReusability/SoftwareRe usability.html.

[4] D. K. Schneider, "Instructional Design Models and Methods," presented at the Online Learning in Diplomacy Workshop, Geneva, 30th May 2006.

[5] R. Gagne, The Conditions of Learning and Theory of Instruction, 4th Ed., New York: Holt, Rinehart and Winston, 1985.
[6] D. A. Wiley, "Connecting learning objects to instructional design theory: A definition, a metaphor, and a taxonomy," in D. A. Wiley Ed., The Instructional Use of Learning Objects: Online Version.

[7] D. Stoilescu, "Modalities of Using Learning Objects for Intelligent Agents in Learning", Interdisciplinary Journal of E-Learning and Learning Objects, vol. 4, 2008.

[8] E. D. Wagner, "The New Frontier of Learning Object Design, The E-Learning Developers' Journal, June 2002, pp. 1-8.

[9] A. L. Chiappe, Y. S. Cifuentes, and H. Y. R. Rodriguez, "Towards an instructional design model based on learning objects," Education Technology Research Development, vol. 55, pp. 671-681.

[10] IEEE Standard for Learning Object Metadata, Standard No. 1484.12.1-2002.

[11] J. L. Mitchell and N. Farha, "Learning Object Metadata: Use and Discovery," in A. Koohang and K. Harman Eds., Learning Objects. Standards, Metadata, Repositories and LCMS, ch.1, pp. 1-40, Santa Rosa, California: Informing Science Press.

[12] F. Neven and E. Duval, "Reusable Learning Objects: A Survey of LOM-based Repositories," Multimedia'02, December 1st -6th, 2002, Juan-les-Pins, France, ACM 1-58113-620-X/02/00012.

[13] J. E. Agaba, B. Kanagwa, D. Tuheirwe, and S. Lunkuse, "Improving Learning objects reusability through automatic generation of web services," in Proc. 7th International Conf. on Computing and ICT Research, August 2011.

[14] Z. Cebeci, E. Yoldas, and M. Kara, "TrAgLor: A LOM-Based Digital Learning Objects Repository for Agriculture," in Proc. 4th International Scientific Conf. on E-Learning and Software Education, I. Roceanu Ed., ISBN: 978-973-749-362-0, University Publishing House, Bucharest, Romania, pp. 125-129.

[15] S. Kell, "Component Adaptation and Assembly Using Interface Relations," OOPSLA/SPLASH'10, October 17-21, Reno/Tahoe, Nevada, USA.

[16] G. T. Hieneman and H. O. Ohlenbusch, "An Experiment in Component Adaptation," ICSE, 2000.

[17] A. Battou, A. El Mezouary, C. Cherkaoui, and D. Mammass, “An Adaptive Learning System Architecture based on a Granular Learning Object Framework," International Journal of Computer Applications, vol. 32, no. 5, pp. 18-26, October 2011.

[18] L. Mortimer. Learning objects of desire: promise and practicality. Learning Circuits. [Online]. Available: http://www.learningcircuits.org/2002/apr2002/mortimer.html

[19] Wisconsin Online Resource Center-WORC. [Online]. Available: http://wisconline.com

[20] G. E. Krull and B. Mallison, "Learning Objects Metadata and Learning Object Repositories," in Proc. e/merge 2004-Blended Learning in Southern Africa, June 28-July 102004.

[21] Instruction at FSU Handbook 2011.

[22] S. Downes, "Design and Reusability of Learning Objects in an Academic Context: A new Economy of Education?" United States Distance Learning Association Journal, vol. 17 no.1, January, 2003.

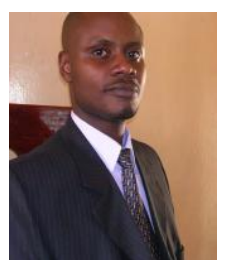

Joab E. Agaba is a first year PhD student at Makerere University. He holds a masters in computer science, and a bachelor of science from Makerere University. His main research interests are in e-learning and instruction design using learning objects.

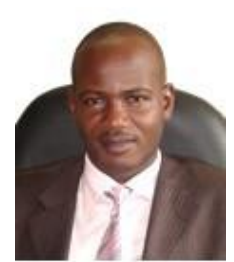

Jude T. Lubega is the deputy vice chancellor of at Uganda Technology and Management University and a seasoned researcher. He holds a $\mathrm{PhD}$ in information technology from University of Reading. His main research interests are in e-learning and instruction design using learning objects. 